\title{
LOS MANUSCRITOS DEL BUSCÓN DE QUEVEDO
}

De la Historia de la vida del Buscón llamado don Pablos se ha venido teniendo como único texto, durante casi tres siglos, el impreso en Zaragoza, el año de 1626, por Pedro Verges, a costa del editor Roberto Dupont. De él derivan todas las ediciones hasta $185^{2}$, año en que publicó el suyo don Aureliano Fernández Guerra y Orbe ${ }^{1}$, intentando depurarlo y corrigiendo algunos pasajes corruptos.

Ninguna de las ediciones anteriores señala variantes que indiquen haberse tenido presente otra redacción. En lo que alcanzan nuestros conocimientos bibliográficos, puede asegurarse que hasta esa fecha nadie apuntó la existencia de manuscrito alguno de la obra, mejor o peor. El texto de Fernández Guerra siguió considerándose como el más puro durante seis decenios.

Pero en 1909 el hispanista Foulché-Delbosc oyó hablar en Madrid de un códice que poseía Menéndez y Pelayo. Inmediatamente escribió al docto erudito preguntándole sobre la certeza de ese rumor. Menéndez y Pelayo le respondió, el 30 de septiembre de 19o9, lo que copiamos:

Sin duda debí de expresarme con poca claridad cuando el amigo... entendió que yo poseía un manuscrito de $E l$ Buscón. Lo que tengo no es el manuscrito, sino las variantes copiadas de él por D. Aureliano Fernández Guerra para la segunda edición que proyectaba de su Quevedo.

En cuanto al ms. mismo, diré a $V$. lo que sé y recuerdo. Le vi por primera vez en 1876 , cuando le poseía D. Juan José Bueno, Bibliotecario de la Universidad de Sevilla y literato bastante conocido. En su testamentaría lo adquirió Asensio que le prestó a D. Aureliano para que sacara las variantes. Más adelante Asensio, deseando ganarse la voluntad de Cánovas con algún obsequio, le hizo el precioso regalo de este códice que Cánovas nos mostraba con natural satisfacción a sus amigos. Después de su muerte y de la dispersión de su librería, ignoro a cuál de sus herederos habrá ido a parar esta alhaja, aunque he procurado con ahinco averiguarlo. No recuerdo si está citado en el destartalado catálogo de los libros de Cánovas, ni quiero interrumpir esta carta por tan poca cosa.

1 BAAEE, vol. XXIII, págs. 485528 . 
El códice, de tamaño muy pequeño, como los clásicos elzevirianos o las ediciones Diamante, era un verdadero primor, una monada. No era autógrafo de Quevedo ni tenía notas suyas. Parecía un ejemplar de regalo, escrito de muy gallarda letra bajo la inspección de su autor.

Tengo en Madrid las variantes con otros papeles para la edición de Quevedo. Mi vuelta se retrasará hasta el día 15 de Octubre, porque están haciendo obra en mis habitaciones de la Academia de la Historia. Pero en cuanto vuelva, haré copiar dichas variantes, las cotejaremos Bonilla y yo, y las recibirá V. cuanto antes en París o donde se hallare.

Falleció don Marcelino sin cumplir la promesa, pero su discípulo Bonilla transcribió minuciosamente "sur un autre exemplaire de la même édition" las variantes y se las remitió a Foulché-Delbosc. En presencia de ellas publicó, dando a conocer algunas, sus notas sobre el Buscón ${ }^{2}$, y en el mismo año una edición en la cual incorporaba al conocido texto de 1626 todo lo facilitado por Bonilla, amén de ciertas correcciones de su propia minerva ${ }^{3}$.

Américo Castro, que había impreso un Buscón para Clásicos castellanos $^{4}$ y que estaba muy interesado en los problemas textuales, hizo una larga reseña de la edición de Foulché (RFE, V, 1918, págs. 405-410), en la cual, reconociendo que "esas variantes enmiendan y dan sentido a infinidad de pasajes de la edición príncipe", y que "en muchos casos es posible intentar ahora una interpretación mucho más acertada", rechaza la apreciación de Foulché de que con ellas poseíamos el "texte inaltéré de Quevedo", afirmando que, "por importantes que sean dichas variantes..., su valor... no puede ser otro que el de notas sueltas tomadas por Fernández Guerra". Como en 1918 aún no podían consultarse los fondos de la Biblioteca de Menéndez y Pelayo, entre los cuales, según Foulché, se hallaban las variantes citadas, don Américo aplazaba, hasta que estuvieran abiertos al público, verificar "exactamente la forma como ha sido hecha esta edición".

Así queda el asunto hasta ocho años después. Artigas, bibliotecario de Santander, informa a Castro, en marzo de 1926, del hallazgo de un manuscrito del Buscón en la biblioteca de don Marcelino, y en el mismo año publica en el $B B M P$ una descripción del códice. ¡Cosa extraña, que en tantos años no se hubiera enterado Artigas de la existencia de tan precioso manuscrito entre los fondos, relativamente escasos, de la biblioteca que regentaba! Como es natural, el hallazgo acució a Castro para editarlo en seguida, advirtiendo, en una breve

2 R. Foulché-Delbosc, "Notes sur le Buscón”, RHi, XLI, 1917, págs. 265-291.

${ }^{3}$ La vida del Buscon por Don Francisco de Queuedo Villegas. G. P. Putnam's Sons, New York, 1917. $4^{\circ} ; 1 x+[1]+207+[5]$ págs. (El volumen se imprimió en París).

4 El primer Buscón de Castro es de 1911 (Clás. cast., vol. 5). 
noticia preliminar, que "muda y mejora esencialmente el texto tradicionalmente conocido" 5 .

Don Roberto Selden Rose venía preparando desde muchos años antes una nueva edición del Buscón, la cual vió la luz pública poco después que la de Castro ${ }^{6}$. Según sus noticias, dispuso para la fijación del texto, amén de la impresión zaragozana de 1626 , de un cuaderno existente en la biblioteca de Menéndez y Pelayo titulado Variantes que resultan de un precioso manuscrito de los primeros años del siglo xvii, que posee el distinguido poeta sevillano Juan José Bueno, copiado allí por Selden Rose en mayo de 1914, y del manuscrito de Santander facilitado por Artigas antes de 1926.

Chocan, en verdad, dos cosas: que Américo Castro no pudiera consultar los libros de Menéndez y Pelayo en 1917 y sí Selden Rose en 19I4; que el ms. nuevo fuera comunicado a Castro en marzo de 1926 y Selden Rose tuviera copia un año antes.

Para Selden Rose, el cuaderno Variantes que resultan... es fidelísima e íntegra transcripción de los desacuerdos entre el códice de Bueno y la edición de 1626; lo publicado por Foulché-Delbosc en 1917. El criterio seguido por Rose en su edición (elegir como base el texto impreso de ${ }_{1626}$ y anotar al pie de página las variantes de los dos mss.) mereció acres censuras de Castro ${ }^{7}$, el cual estimaba que, existiendo tres redacciones de la novela -representadas por el $\mathrm{ms}$. Bueno, el de Santander y la edición zaragozana-, era absurdo "mezclarlas o fundirlas para construir sobre ellas un texto nuevo".

Así las cosas, salen a la luz pública las Obras completas de Quevedo en edición crítica preparada por Astrana Marín ${ }^{8}$. Ya en la Introducción general nos manifiesta con respecto al Buscón (pág. xvi):

Damos el texto puro, integro, según la redacción primitiva y los posteriores retoques de Quevedo, a la vista del precioso manuscrito que perteneció a don Juan José Bueno y de la no menos preciosa transcripción hecha por don Bartolomé José Gallardo del riquísimo códice número 179 de la catedral de Córdoba, La vida del Buscón, llamado don Pablos, por don Francisco Gómez de Quevedo, dividido en tres libros, el último de los cuales se intitula Libro tercero de la Vida del Buscavidas.

- En esta $2^{n}$ edición de Castro se promete un volumen II que no llegó a salir. A partir de 1939 la colección Clás. cast. suprimió las dos ediciones de Castro, sustituyéndolas por un volumen, prologado por Luis Santamarina, en el cual se reproduce el texto de la primera edición zaragozana.

- Historia de la Vida del Buscon, Llamado Don Pablos; Exemplo de Vagamundos y Espejo de Tacaños, por Don Francisco de Quevedo Villegas... Edición crítica por Don Roberto Selden Rose... Lib. y Casa edit. Hernando, Madrid, 1927, 4; $405+[3]$ págs.

` En la reseña publicada en $R F E$, XV, 1928, págs. 186-19o.

- Obras completas de don Francisco de Quevedo Villegas... M. Aguilar edit., Madrid, 1932. Vol. I, Prosa; vol. II, Verso. 
Según afirma en otro lugar (vol. II, pág. Xxir), "tres textos hay... del Buscón, ninguno autógrafo: la Vida del Buscón, por don Francisco Gómez de Quevedo, manuscrito que perteneció a don Juan José Bueno; La vida del Buscón llamado don Pablos, por don Francisco de Quevedo, y la Tercera parte de la Vida del Buscavidas, copia de don Bartolomé José Gallardo del códice 179 de la Catedral de Córdoba". De estos tres mss. deja aparte el de Bueno y añade que La vida del Buscón coincide, "fuera de algunas" variantes sin importancia y las erratas", con la edición de Zaragoza, 1626, mientras que la Tercera parte concuerda "con ligerísimas discrepancias" con el ms. existente en la Biblioteca de Menéndez y Pelayo, en Santander.

Hay, pues, según Astrana, cuatro mss. del Buscón. Para mayor claridad vamos a separarlos perfectamente:

I) Códice de Bueno.

2) La vida del Buscón llamado don Pablos, por don Francisco Gómez de Quevedo: coincide, según Astrana, con la primera edición.

3) Tercera parte de la Vida del Buscavidas, copia hecha por Gallardo del códice que fué de la Catedral de Córdoba: coincide, según Astrana, con el ms. que existe en Santander.

4) Códice de Santander (biblioteca de Menéndez y Pelayo).

Al acudir al Catálogo de manuscritos que incluye Astrana en las págs. 1300-1301 del vol. II de su edición, nos encontramos con la sorpresa de que sólo registra los mss. 1 (núm. 120), 3 (núm. 121 ) y 4 (núm. 122): ha desaparecido en la bibliografía el ms. 2, sobre el cual volveremos más adelante.

El primer número de los de Astrana es un ms. titulado La vida del Buscón. Según el bibliógrafo, perteneció a Bueno, "quien lo prestó a Fernández Guerra para que sacara las variantes. Éstas, con el título de Variantes que resultan de un precioso manuscrito de los primeros años del siglo xvii, que posee el distinguido poeta sevillano Juan José Bueno, fueron entregadas por don Luis Valdés con los demás papeles de Fernández Guerra a don Marcelino Menéndez y Pelayo para la edición de Quevedo que proyectaba. Y parece que no le fueron devueltas, pues tanto don Luis como yo las buscamos inútilmente". Pasó luego a manos de don José María Asensio y a las de don Antonio Cánovas del Castillo. Cuando escribía Astrana, creía poseer este manuscrito.

El segundo códice de los reseñados contiene una copia hecha por Gallardo de un ms. que fué en tiempos de la Catedral de Córdoba y que ya no se conservaba en ella a principios de este siglo. La copia de Gallardo pertenecía también a Astrana.

Finalmente, registra en su catálogo el ms. de Santander, ya publicado por Rose y por Castro.

En presencia, pues, de este magnífico material, estaba Astrana Marín en condiciones de ofrecer un texto mejor que todos los cono- 
cidos hasta entonces del Buscón. Sin embargo, el impreso es una redacción hecha tomando pasajes de unos y otros indiferentemente y sin valorar cada uno de por sí.

Repasando las únicas cincuenta y dos notas que consagra a variantes (frente a los centenares de Rose y Foulché), advertimos en primer lugar que no se dió cuenta de que el ms. de su propiedad, al que llama Códice de Bueno, no es el que con igual nombre utilizaron Rose y Foulché-Delbosc a través de las variantes sacadas por Fernández Guerra, aunque coincida con él. Allá van estas tres muestras, harto probatorias, sólo de una página:

\section{Cód. Bueno (Fernández Guerra)}

Por estas y otras niñerías estuvo preso; y rigores de justicia (de que hombre no se puede defender) le sacaron por las calles. En lo que toca de medio abajo tratáronle aquellos señores regaladamente. Iba a la brida en bestia segura y de buen paso, con mesura y buen día. Mas de medio arriba etc.: que no hay ni es que decir para quien sabe lo que hace un pintor de suelo [sic] en Jas costillas. Diéronle doscientos escogidos, que de allí a seis años se le contaban por encima de la ropilla. Más se movía el que se los daba que él, cosa que pareció muy bien. Divirtióse algo con las alabanzas que iba oyendo de sus buenas carnes; le estaba de perlas lo colorado. Mi madre, pues, no tuvo calamidades...

Tuuo muy buen parecer para letrado, mujer de amigas de cuadrilla y de pocos enemigos, porque hasta los tres del alma aún no los tuvo por tales: persona de valor y conocida por quien era. Padeció grandes trabajos...

Un día, alabándomela una vieja que me crió, decía que era tal su agrado, que hechizaba a cuantos la trataban. Y decía (no sin sentimiento): En su tiempo, hijo, cran los virgos como soles, unos

\section{Cód. Bueno (Astrana)}

Por estas y otras niñerías estuvo preso, aunque, según a mí me han dicho después, salió de la cárcel con tanta honra, que le acompañaron doscientos cardenales, sino que a ninguno llamaban eminencia. Las damas diz que salían por verle a las ventanas, que siempre pareció bien mi padre a pie y a caballo. No lo digo por vanagloria, que bien saben todos cuán ajeno soy della. ¡Mi madre, pues, no tuvo calamidades!...

Tuvo muy buen parecer, y fué tan celebrada, que en el tiempo que ella vivió todos los copleros de España hacían cosas sobre ella. Padeció grandes trabajos...

Un día, alabándomela una vieja que me crió, decía que era tal su agrado, que hechizaba a todos cuantos la trataban; sólo diz que le dijo no sé qué de un cabrón y volar, lo cual la puso cerca de 
amanecidos y otros puestos, y los que la diesen plumas con que lo más en un día mismo amaneci- hiciese en público. Hubo fados y puestos. Hubo fama... ${ }^{9}$ ma. . . ${ }^{10}$

No hay un solo editor que teniendo a la vista variantes de tal importancia, prescinda de ellas sin advertirlo. ¡Y nótese que todo esto estaba ya impreso por Selden Rose! Astrana no manejó el auténtico ms. Bueno, ni siquiera las variantes publicadas. El manuscrito que fué de Menéndez y Pelayo no aparece mencionado en las notas. $Y$ eso que hubiera evitado errores de lectura como "diz que le dijo no sé qué de un cabrón y volar" (ed. de ${ }_{1} 626$ ) en vez de "diz que $s e$ dijo" (ms. de Santander y, como luego veremos, de Córdoba).

Otro códice, del cual afirmó Astrana (vol. II, pág. xxII) que coincide, "fuera de algunas variantes sin importancia y las erratas", con la primera edición, no se ha utilizado tampoco, ni en puridad había forma de utilizarlo, porque no ha existido nunca. Sin duda un trastrueque de notas le hizo desdoblar el códice cordobés, llamándole unas veces con este título y otras con el de Libro tercero de la vida del Buscavidas (págs. 71, 78, 79, 88 y 91). La confusión resulta verdaderamente incomprensible cuando de un mismo pasaje señala variantes del ms. cordobés y del Libro tercero:

El "Libro tercero de La vida del Buscavidas", ya citado, incrusta aquí el siguiente pasaje, suprimido por delicadeza en el ms. de Bueno, en la primera parte del códice cordobés y en la edición príncipe: "Eché de ver que unos parecían tripas de los que tiraban. Otros, acabándoseles la saliva, pedían prestados a las narices sus tuétanos, y venían con unas balas de mocos tan recios, que hacían batería y señal en la capa" (pág. 79).

La edición príncipe suprimió este extenso pasaje y estafa, diciendo solamente los estudiantes: "Como hemos de servir a v. m. en Alcalá, quedamos ajustados en el gasto". La lección quedó de esta suerte muy corrupta. El códice cordobés, en cambio, aunque acepta la supresión, mejora así el texto: "Decían los estudiantes: -iCómo hemos de servir a v. m. en Alcalá!" Y luego aparte: "Quedamos asustados con el gasto". En el "Libro tercero" del mismo códice: "Quedamos asustados de ver el gasto" (pág. 78) .

Ni el texto recompuesto por Foulché-Delbosc, ni el muy errado de Selden Rose, ni el de Astrana, ofrecen garantías al estudioso de Quevedo. Se impone la tarea de volver la vista a los manuscritos y a la primera edición para realizar con criterio científico la labor crítica imprescindible: en las páginas siguientes damos una ligera noticia bibliográfica de los códices del Buscón.

- Ed. Selden Rose, págs. 44-45.

${ }^{10}$ Ed. Astrana Marín, pág. [69]. 


\title{
I. Manuscrito de don Juan José Bueno
}

\author{
Historia || de la || Vida del Buscon. || llamado don Pablos || egemplo \\ de vagamundos || y espejo de tacaños. || por $\|$ Dn. Fran. ${ }^{\circ}$ de Que- \\ vedo $\|$ y Villegas.
}

Portada copiada (vuelta en blanco), de letra de la primera mitad del siglo xix, bastante tosca: se conoce que, perdida la hoja original, se hizo la sustitución al encuadernarlo en tafilete de color oliva hacia 1840 , añadiéndose entonces, asimismo, una tabla en tres folios. La letra del ms. es clara y primorosa. Mide $97 \mathrm{~mm}$. [1] $+217+[3]$ fols. Lleva al fin una carta de don Aureliano Fernández Guerra. Ex libris: Antonio Cánovas del Castillo.

He aquí, por primera vez descrito, el famoso Códice Bueno, citado y recitado por eruditos que nunca han alcanzado a verlo. Puede afirmarse que desde 1854 nadie ha vuelto a trabajar con él directamente. Conocíamos su existencia desde hace años y disfrutamos asimismo de reproducción fotográfica íntegra gracias a la gentileza de su propietario.

La historia del peregrino volumen es, en pocas palabras, la siguiente. Aparece en 1854 en manos de don Juan José Bueno, bibliotecario de la Universidad de Sevilla, el cual, por mediación de don Julián de Álava, lo envió don Aureliano Fernández Guerra para que lo utilizase en su edición de Quevedo, según testimonia la carta que va unida al tomito ${ }^{11}$. A la muerte de Bueno, según dice Astrana Marín (vol. II, pág. 1 301 ), fué ofrecido en venta a Fernández Guerra. Lo adquirió de la testamentaría don José María Asensio: la carta que hemos publicado rectifica el aserto de Menéndez y Pelayo de que fué este poseedor quien prestó el manuscrito a don Aureliano para obtener las variantes. Asensio regaló el precioso volumen a don An-

${ }^{11}$ He aquí el texto de la carta:

«Sr. D. Juan José Bueno.

"Madrid 10 de julio de 1854 :

"Mi amigo muy querido: escribo en la misma carta que acabo de recibir de mi antiguo y excelente compañero D. Diego Roca de Togores á cuyas manos pasé ayer la carta de $V$. que por la mañana y con gran retraso vino a las mias. Es primo hermano del Sr. Ministro de Marina, vive con él, y nadie pudiera darme noticias más exactas, aun cuando veo que no son nada satisfactorias.

«Hace dos meses que Julian de Alava me entregó el Buscon con que tan generosamente me ha franqueado $V$. para enriquecer mi edicion de Quevedo. Traté de que Julian mismo la volviera á su bizarro dueño; pero tengo que copiar casi todo el manuscrito y cuando nuestro amigo marchó, aún quedaba una mitad por hacer. La letra es del amanuense de Quevedo y sospecho que nuestro D. Francisco la hiciese sacar para obsequiar en 1624 al Duque de Medinasidonia.

«Sea V. indulgente con mi morosidad en bien de las letras españolas.

"Sabe V. que es suyo de todas veras afmo. amigo y s. s. q. b. s. m. 
tonio Cánovas del Castillo $\left(\uparrow_{1} 897\right)$, y a la muerte de éste pasó a sus herederos; al hacer las particiones correspondió el volumen a don Antonio Cánovas Vallejo (Kaulak): a él lo compró don José Láraro.

Todo lo que hasta ahora se sabía de este importantísimo manuscrito procedía de las variantes anotadas por Fernández Guerra, aprovechadas parcialmente por Foulché-Delbosc y totalmente por Selden Rose, aunque en forma poco clara y aun confusa. A nuestro juicio, es el texto más puro del Buscón y merece ser impreso en su integridad.

\section{Manuscrito de Meníndez y Pelayo}

La Vida del Busca Vida || Por otro nombre D. Pablos. \|Compuesto por D. fran ${ }^{\text {co. }}$ de queuedo.

Portada. [Dedicatoria]. Texto. [1] +56 fols. Letra del siglo xvir. Copia en que hay incorrecciones del escribiente. Artigas (Catálogo de los manuscritos..., núm. 101) lo describe así: "Este ms. ha debido formar parte de colecciones de papeles, pues tiene borradas cuatro numeraciones más, dos de ellas iguales, que comprenden desde el número 32 al 85 , otra del 162 al 233 y otra del 180 al 215 . Los folios $1^{\circ}$ y último sólo tienen la numeración actual".

Aun con los errores del copista, es un texto bastante bueno. $\mathrm{Ha}$ sido escrupulosamente editado, modernizando la ortografía, por Américo Castro en 1927. Las variantes están aprovechadas en la edición de R. Selden Rose.

\section{Manuscrito de Córdoba-Gallardo}

La Vida de el buscon, lla \| mado Don Pablos por don || Franco. Gomez de quebedo.

Portada. [Dedicatoria]. Texto dividido en tres libros, el último de los cuales se rubrica así: Libro tercero de la vida del Busca Vidas. [1] + 110 fols. Letra del primer tercio del siglo xvir. Hay incorrecciones del escribiente. Encuadernación de la época, en pergamino; en el lomo dice: Vida del Gran Tacaño de Quevedo. En la guarda hay una nota en tinta y otra a lápiz; la primera, muy borrosa y contemporánea al ms., reza así: "Diose de orden del Licdo... min. Murillo Rector de St. andres de Cor"ui."; la segunda, indudablemente de Gallardo, sólo dice: "N. 179 ".

Según Astrana Marín, tenía en su poder una copia de este manuscrito hecha por Gallardo, "que lo copió de la biblioteca de la Catedral de Córdoba"; en dicha Catedral no existía ya antes de $193^{\circ}$. Adquirido hace años por el docto bibliófilo don Eugenio Asensio, ha pasado a formar parte de una colección particular. El texto está más cercano al ms. de Menéndez y Pelayo que al de Bueno. Astrana utilizó la copia hecha por Gallardo, pero ya hemos hecho notar las inexplicables confusiones con que la cita en las variantes; llega hasta a decir que en el códice de Córdoba hay dos copias del Buscón. 
IV. Supuesto manuscrito de don J. J. Bueno

La Vida del Buscon || llamado Don Pablos \| por Don fran. ${ }^{c o}$ Gomez de Queuedo.

Ms. en $16^{\circ}$. Letra del amanuense de Quevedo, al parecer de Messía de Leiva. 282 págs. Copia hecha hacia 1622 ó 1623 .

No tenemos de este manuscrito más noticias que las suministradas por Astrana Marín, quien lo confunde con el que perteneció a Juan José Bueno. Ya hemos visto que el de Bueno es otro. Dice Astrana:

Parece que anduvo el tomito por los baratillos de Madrid, donde, tras pasar por muchas manos, recientemente lo adquirimos nosotros. La joyita no posee apunte alguno ni ex libris de Cánovas; pero se infiere bien ser el ms. de Bueno por contener dentro de sus hojas una cuartilla doblada, con el canto dorado, extraída sin duda de algún libro, y en ella una nota autógrafa de Bueno sobre el dómine Cabra, que transcribimos en la edición.

Las indicaciones "los baratillos de Madrid" y "tras pasar por muchas manos" son harto imprecisas. Al redactar estas notas me dice Astrana que el ms. le fué sustraído por una criada hacia 1934 ó 1935. Ninguno de los libreros de viejo madrileños ni de los bibliófilos o coleccionistas a quienes he preguntado ha tenido noticia de tal códice: lamentemos, aunque no mucho, su pérdida, al parecer definitiva ${ }^{12}$.

Estamos hoy, pues, en mejores condiciones que nunca para llevar a cabo una buena edición del Buscón. Localizados los tres manuscritos fundamentales y pudiendo utilizarlos sin restricciones y sin acudir a copias, podrá el estudioso futuro contar con un texto depurado de tan importante pieza literaria. Su interés aconseja que se reproduzcan íntegramente los mss. Bueno y Córdoba-Gallardo, ya que del de Santander existe la excelente edición de Américo Castro.

Como piedra de toque y para que pueda juzgarse del interés que presentan, añadimos a estas páginas el primer capítulo del Buscón en todos los textos antiguos conocidos. Queda en prensa una edición fiel del auténtico manuscrito de Bueno.

Madrid.

Antonio Rodríguez-MoÑino

12. Aunque estamos en desacuerdo con la valoración que hace de los textos del Buscón y con su modo de editar las obras quevedianas, esta diferencia es puramente científica y para nada roza a la estima personal que nos merece Astrana. 


\section{GAPÍTULO PRIMERO DEL BUSCÓN, SEGÚN LOS TRES}

ZARAGOZANA

I

\author{
Ms. DE J. J. BuENO \\ (según el códice original) \\ Libro primero
}

Capitvlo primero en que cventa quien es el Bvscon

Yo Señora soy de Segouia, mi padre se llamo Clemente Pablo, natural del mismo pueblo (Dios le tenga en el cielo) fue tal como todos dizen de officio barbero, aunque eran tan altos sus pensamientos de que se corria de que le llamassen assi diciendo que el era tundidor de mexillas y sastre de barbas. Dizen que era de muy buena cepa, y segun el bebia es para creer.

Estuuo cassado con Aldonza de San Pedro, hija de Diego de San Juan, y nieta de Andres de San Cristoual sospechauasse en el pueblo, que no era christiana vieja (aun viendola con canas y rota) Aunque ella por los nombres, y sobrenombres de sus passados quiso esforzar que era decendiente de la gloria.

Tubo muy buen parecer para letrado: muger de amigas y quadrilla y de pocos enemigos, por que asta los tres del alma aun no los tubo por tales; persona de valor, y conocida por quien era. Padecio grandes trauajos recien casada, y aun despues por que malas lenguas daban en decir, que mi padre metia el dos de bastos, para sacar el As de oros. Probosele que a todos los que acia la barba a nauaja mientras les daua con el agua leuantandoles la cara para el lauatorio vn mi hermanico de siete años les sacaua muy a su saluo los tuetanos de las faldriqueras. Murio el angelico de vnos azotes que le dieron en la carcel. Sintiolo mucho mi padre, por ser tal, que robaba a todos (las voluntades).

Por estas y otras niñerias estuvo preso, y rigores de Justicia, (de que ombre no se puede defender,) le sacaron por las calles. En lo que toca de medio auaxo trataronle aquellos señores re-
II

\author{
Ms. de Menéndez y Pelayo \\ (según la ed. de Castro, 1927) \\ Libro Primero \\ Capítulo I. Cuenta quién es \\ y de dónde
}

Yo soy, señor, natural de Segovia. Mi padre se llamó Clemente Pablo (Dios le tenga en el cielo). Fué tal como todos dicen; su oficio fué de barbero; aunque eran tan altos sus pensamientos, que se corría que le llamasen así, diciendo que él era tundidor de mejillas y sastre de barbas. Dicen que era de muy buena cepa; y, según él bebió, puédese muy bien creer.

Estuvo casado con Aldonza de San Pedro, hija de Diego de San Juan y nieta de Andrés de San Cristóbal. Sospechábase en el pueblo que no era cristiana vieja, aunque ella, por los nombres y sobrenombres de sus pasados, quiso probar que era descendiente de la letanía.

Tuvo muy buen parecer, y fué tan celebrada, que en el tiempo que ella vivió, casi todos los copleros de España hacian cosas sobre ella. Padeció grandes trabajos recién casada, y aun después, porque malas lenguas daban en decir que mi padre metía el dos de bastos para sacar el dos de oros. Probósele que a todos los que hacía la barba a navaja, mientras les daba con el agua, levantándoles las caras para el lavatorio, un mi hermanico de siete años les sacaba, muy a su salvo, los tuétanos de las faltriqueras. Murió el angelito de unos azotes que le dieron dentro de la cárcel. Sintiólo mucho mi padre (buen siglo haya), por ser tal, que robaba a todos las voluntades.

Por estas y otras niñerías estuvo preso; aunque, según a mí me han dicho después, salió de la cárcel con tanta honra, que le acompañaron doscientos cardenales, sino que a ninguno llama- 


\section{MANUSCRITOS CONOCIDOS Y EL TEXTO DE LA EDICIÓN DEL AÑO 1626}

III

\author{
Ms. de Córdoba-Gallardo \\ (según el códice original) \\ Libro Primero
}

Capítulo .j. en que quenta quien es y de donde

Yo señor soy natural de Segouia, mi Padre se llama, clemente Pablo, natural del mesmo pueblo Dios le tenga en el çielo fue tal con todos diçen de offiçio barbero aunque heran tan al. tiuos sus pensamientos que se corria que le llamassen assi diçiendo que el hera tundidor de mexillas y sastre de barbas diçen era de muy buena cepa y segun el veuia es cossa para creer

estuuo casado con adonça de Sant Pedro hija de diego de San Juan y nieta de andres de San christoual. Sospechauasse en el pueblo que no era christiana vieja, aunque ella por los nombres y sobrenombres de sus passados quisso prouar que hera deçendiente de la letania.

Tuuo muy buen pareçer y fue tan çelebrada que en el tiempo que ella vivio cassi todos los copleros de españa hazian cossas sobre ella. Padeçio grandes trauajos rezien cassada y aun despues porque malas lenguas deçian que mi Padre metia el dos de bastos para sacar el tres de oros. Probosele que a todos los que haçia la varua les dexaua con el agua. Leuantandoles la cara para el lauatorio vn mi hermanito de siete años le sacaua muy a su gusto los tuetanos de las faldriqueras murio el angelito de vnos açotes que le dieron en la carcel sintiolo mucho mi Padre por ser tal que rrouaua a todos las voluntades

por estas y otras niñerias estuuo presso aunque segun a mi me an dicho despues salio de la carçel con tanta honrra que le acompañaron doçientos cardenales avnque a ninguno llamauan
IV

Edición de Zaragoza, 1626

(según la reimp. de Castro, 1911)

Capítulo 1. En que cuenta quién es y de dónde

Yo, señor, soy de Segovia; mi padre se llamó Clemente Pablo, natural del mismo pueblo -Dios le tenga en el cielo-. Fué tal, como todos dicen: de oficio barbero; aunque eran tan altos sus pensamientos, que se corría le llamasen así, diciendo que él era tundidor de mejillas y sastre de barbas. Dicen que era de muy buena cepa, y, según él bebía, es cosa para creer.

Estuvo casado con Aldonza Saturno de Rebollo, hija de Octavio de Rebollo Codillo y nieta de Lépido Ziuraconte. Sospechábase en el pueblo que no era cristiana vieja, aunque ella, por los nombres de sus pasados, esforzaba que descendía de los del triunvirato romano.

Tuvo muy buen parecer, y fué tan celebrada, que en el tiempo que ella vivió, todos los copleros de España hacían cosas sobre ella. Padeció grandes trabajos recién casada, y aun después, porque malas lenguas daban en decir que mi padre metía el dos de bastos por sacar el as de oros. Probósele que a todos los que hacía la barba a navaja, mientras les daba con el agua, levantándoles la cara para el lavatorio, un mi hermano de siete años les sacaba, muy a su salvo, los tuétanos de las faldriqueras. Murió el angelico de unos azotes que le dieron en la cárcel. Sintiólo mucho mi padre, por ser tal, que robaba a todos las voluntades.

Por estas y otras niñerías estuvo pre. so; aunque, según a mí me han dicho después, salió de la cárcel con tanta honra, que le acompañaron docientos cardenales, sino que a ninguno llama- 
galadamente. Iba a la brida en bestia segura y de buen passo con mesura y buen dia. Mas de medio arriba ecetera, que no ay mas que decir, para quien saue lo que haze vn pintor de suela en vnas costillas. Dieronle docientos escogidos, que de alli a seis años se le contauan por encima de la ropilla. Mas se mouia el que se los daua, que el: cosa que parecio muy bien. Diuirtiose algo con las alabanzas, que iua oyendo de sus buenas carnes, que le estaua de perlas lo colorado.

Mi madre pues no tuuo calamidades? Vn dia alabandomela vna vieja, que me crio, decia, que era tal su agrado, que echizaba a quantos la trataban. $Y$ decia (no sin sentimiento) En su tiempo hijo, eran los virgos como soles, vnos amanecidos, y otros puestos, y los mas en vn dia mismo amanccidos, y puestos. Vbo fama, que reedificaua doncellas, resuscitaua cauellos, encubriendo canas; empreñaba piernas con pantorrillas postizas. $Y$ con no tratarla nadie que se le cubriesse pelo solas las caluas se la cubria. Por que azia cauelleras; poblaba quixadas con dientes, al fin viuia de adornar ombres, y era remendona de cuerpos:

vnos la llamaban zurzidora de gus tos, otros algebrista de voluntades desconcertadas, otros juntona: qual la llamaba enflautadora de miembros, y qual texedora de carnes; y por mal nombre Alcagueta. Para vnos era tercera, primera para otros, y flux para los dineros de todos. Ver pues con la cara de risa, que ella oiia esto de todos era para dar mil gracias a Dios. ban eminencia. Las damas diz que salian por verle a las ventanas, que siempre pareció mi padre muy bien a pie y caballo. No lo digo por vanagloria, que bien saben todos cuán ajeno soy della.

Mi madre, pues, no tuvo calamidades. Un día alabándomela una vieja que me crió, decía que era tal su agrado, que hechizaba a cuantos la trataban; sólo diz que se dijo no sé qué de un cabrón y volar, lo cual la puso cerca de que la diesen plumas con que lo hiciese en público. Hubo fama de que reedificaba doncellas, resucitaba cabe llos y encubría canas.

Unos la llamaban zurcidora de gustos; otros, algebrista de voluntades des concertadas, y por mal nombre la llamaban alcahueta; para unos era tercera y prima para todos, y flux para los dineros de todos. Ver, pues, con la boca de risa que ella oía esto de todos, era para dar mil gracias a Dios.

No me detendré en decir la penitencia que hacía. Tenía un aposento, donde sola ella entraba - y alguna vez yo, que, como era chiquito, podía-, todo rodeado de calaveras, que ella decía que eran para memorias de la muerte, o para voluntades de la vida. Su cama estaba armada sobre sogas de ahorcados, y decíame a mí: “¿Qué piensas? Éstas tengo por reliquias, porque los más de éstos se salvan". 
señoria. Las damas diz que salian por uerle a las ventanas que siempre pareçio bien mi Padre a pic y a cauallo no lo digo por vanagloria que bien sauen todos quan ageno soy della,

mi madre pues no tuuo calamidades vn dia, alauandomela vna vieja que me crio deçia que era tal su agrado que enechiçaua a quantos la tratauan solo diz qua se dixo no se que de vn cabron y volar lo qual la pusso zerca de que la diessen plumas con que lo hiçiesse en publico huuo fama que rreedificaua donçellas y rresuçitaua cauellos encubriendo canas

vnos la llamauan çurçidora de gustos otros aljebristas de voluntades desconçertadas y Por mal nombre alcahueta. Para vnos era primera Terçera para otros y flus para los dineros de todos ver con la cara de rissa que ella oia esto de todos era para dar mill graçias a Dios

no me detendre en deçir la penitenzia que haçia tenia vn apossento adonde ella entraua y algunas veçes como yo era chico Podia todo rrodeado de calaueras que ella deçia que hera para memoria de la muerte y otros para vituperalla que hera para voluntades de la vida su cama estaua armada sobre sogas de aorcados $\mathrm{Y}$ deziame que Pienssas estas tengo Por reliquias porque los mas de estos se saluan ban scñoria. Las damas diz que salian por verle a las ventanas, que siempre pareció bien mi padre, a pie y a caballo. No lo digo por vanagloria, que bien saben todos cuán ajeno soy della.

Mi madre, pues, no tuvo calamidades. Un día, alabándomela una vieja que me crió, decía que era tal su agrado, que hechizaba a todos cuantos la trataban; sólo diz que le dijo no sé qué de un cabrón, lo cual la puso cerca de que la diesen plumas con que lo hiciese en público. Hubo fama de que reedificaba doncellas, resucitaba cabellos, encubriendo canas.

Unos la llamaban zurcidora de gustos; otros, algebrista de voluntades desconcertadas, y por mal nombre alcagüeta y flux para los dineros de todos. Ver, pues, con la cara de risa que ella oía esto de todos, era para más atraerles sus voluntades.

No me detendré en decir la penitencia que hacía. Tenía su aposento, donde sola ella entraba -y algunas veces yo, que como era chico podía-, todo rodeado de calaveras, que ella decía eran para memorias de la muerte, y otros, por vituperarla, que para voluntades de la vida. Su cama estaba armada sobre sogas de ahorcado, y decíame a mí: "¿Qué piensas? con el recuerdo desto aconscjo a los que bien quiero que para que se libren dellas 
Vbo grandes diferencias entre mis padres sobre a quien auia de imitar en el officio. Mas yo que siempre tuue pensamientos de cauallero desde chiquito nunca me aplique a vno ni a otro. Deciame mi padre Hijo, esto de ser ladron no es arte mecanica, sino liberal. $Y$ de alli a vn rato auiendo suspirado, decia. De manos. Quien no hurta en el mundo no viue. Por que piensas que los Alguaciles, y Jueces nos aborrecen tanto? Vnas vezes nos destierran, otras nos azotan, y otras nos cuelgan? (no lo puedo decir sin lagrimas, lloraua como vn niño el buen viejo acordandose de las que le auian batanado las costillas.) Por que no querrian que donde estan vbiesse otros ladrones sino ellos, y sus ministros. Mas de todo nos libro la buena astucia; en mi mozedad siempre andaua por las iglesias, y no de puro buen Cristiano. Muchas vezes me vbieran llorado en el asno si vbiera cantado en el potro. Nunca confessê sino quando lo mandaba la santa madre Iglesia. Preso estuue por pedigueño en caminos, y a pique de que me esteraran el tragar, y de acauar todos mis negocios con diez, y seis marauedis: diez de soga, y seis de cañamo. Mas de todo me a sacado el punto en voca, el chiton y los nones. $Y$ con esto, y mi officio e sustentado a tu madre lo más onrradamente que e podido.

Como a mi sustentado? (dixo ella con grande colera) yo os ê sustentado a vos, y sacado os de las carceles con industria, y mantenido os en ellas con dinero; si no confessauades era por vuestro animo? o por las bebidas que yo os daua? Gracias a mis botes; y si no temiera, que me auian de oyr en la calle, yo dixera lo de quando entre por la chimenea, y os saque por el texado.
Hubo grandes diferencias entre mis padres sobre a quién había de imitar en el oficio; mas yo, que siempre tuve pensamientos de caballero desde chiquito, nunca me apliqué a uno ni a otro. Deciame mi padre: "Hijo, esto de ser ladrón no es arte mecánica, sino liberal"; y de allí a un rato, habiendo suspirado, decía de manos: "El que no hurta en el mundo, no vive. ¿̨Por qué piensas que los alguaciles y jueces nos aborrecen tanto? Unas veces nos destierran, otras nos azotan, otras nos cuelgan, aunque no haya llegado el día de nuestro santo. No lo puedo decir sin lágrimas" -lloraba como un niño el buen viejo, acordándose de las veces que le habían bataneado las espaldas-: "porque no querrían ellos que adonde están hubiese otros ladrones sino ellos y sus ministros. De todo nos libra la buena astucia. En mi mocedad siempre andaba por las iglesias: y no de puro buen cristiano. Muchas veces me hubieran llevado en el asno si hubiera cantado en el potro. Nunca confesé sino cuando lo mandaba la Santa Madre Iglesia; y así, con esto y mi oficio, he sustentado a tu madre lo más honrada. mente que he podido".

"Cómo, ¿a mi sustentado?", dijo ella con gran cólera, que le pesaba de que yo no me aplicase a brujo-; "yo os he sustentado a vos, y sacádoos de las cárceles con industria, y mantenido en ellas con dinero. Si no confesábades, ¿era por vuestro ánimo o por las bebidas que yo os daba? Gracias a mis botes. Y si no temiera que me habían de oír en la calle, yo dijera lo de cuando entré por la chimenea y os saqué por el tejado". Más dijera, según se había encolerizado, si con los golpes que daba no se le desensartara un rosario de muelas de difuntos que tenía. 
huuo grandes diferençias entre mis padres sobre a quien auia de ymitar En el oficio mas Yo que sienpre tuue pensamientos de cauallero desde chiquito) munca me aplique ni a uno ni a otro deçiame mi padre Hijo esto de ser ladron no es arte mecanico sino liueral y de alli a vn rato hauiendo suspirado deçia de manos quien no hurta En el mundo no uiue Porque pienssas que los alguaçiles y alcaldes nos aborreçen tanto vnas ueçes nos destierran otras nos açotan $\mathrm{Y}$ otras nos cuelgan aunque no aya llegado el dia de nuestro Santo, no lo puedo deçir sin lagrimas lloraua como vn niño El buen viejo acordandosse de las ueçes que le auian bataneado las costillas, Porque adonde ellos estan no querrian que vuiesse otros ladrones sino Ellos $\mathrm{Y}$ sus ministros mas de todos nos libro la buena astuçia, en mi moçedad siempre anduue por las Iglessias y no de puro buen christiano muchas me huuieran llorado en el asno si vuiera cantado en el potro nunca confesse sino quando lo manda la santa madre Yglessia y assi con esto y $\mathrm{mi}$ officio e sustentado a tu madre lo mas honrradamente que he podido

(como a mi sustentado. dixo mi madre Con grande colera que le pessaua que yo no me aplicasse a brujo Yo os e sustentado a vos y sacado de las Carçeles con mi Industria y sustentadoos con ella y dinero y si no onfesabades era por vuestro animo o por las veuidas que yo os daua graçias a mis votes y si no temiera que me auian de oir en la calle dixera de quando entre por la chiminea $y$ os saque por el texado mas dixera segun se auia metido en colera si con los golpes que daua no se le vuiera soltado vn rrossario de muelas de difuntos que tenia vivan con la barba sobre el hombro, de suerte que ni aun con mínimos indicios se les averigüe lo que hicieren".

Hubo grandes diferencias entre mis padres sobre a quién había de imitar en el oficio; mas yo, que siempre tuve pensamientos de caballero desde chiquito, nunca me apliqué ni a uno ni a otro. Decíame mi padre: "Hijo, esto de ser ladrón no es arte mecánica, sino liberal"; y de allí a un rato, habiendo suspirado, decía de manos: "Quien no hurta en el mundo, no vive. ¿Por qué piensas que los alguaciles y alcaldes nos aborrecen tanto? Unas veces nos destierran, otras nos azotan y otras nos cuelgan, aunque nunca haya llegado el día de nuestro santo. No lo puedo decir sin lágrimas" -lloraba como un niño el buen viejo acordándose de las veces que le habían bataneado las costillas-; "porque no querrían que adonde están hubiese otros ladrones sino ellos y sus ministros; mas de todo nos libra la buena astucia. En mi mocedad siempre andaba por las iglesias: y no cierto de puro buen cristiano. Muchas veces me hubieran llevado en el asno si hubiera cantado en el potro. Nunca confesé sino cuando lo manda la santa madre Iglesia; y así, con esto y mi oficio, he sustentado a tu madre lo más honradamente que he podido".

“¿Cómo me habéis sustentado?, dijo ella con gran cólera, que le pesaba que yo no me aplicase a bruja-; yo he sustentado a vos y sacádoos de las cárceles con industria, y mantenido en ellas con dinero. Si no confesábades, ¿era por vuestro ánimo o por las bebidas que os daba? Gracias a mis botes. $Y$ si no temiera que me habían de oír en la calle, yo dijera lo de cuando entré por la chiminea y os saqué por el tejado". Más dijera, según se había encolerizado, si con los golpes que daba no se le desensartara un rosario de muelas de difuntos que tenía. 
Metilos en paz; diciendo, que yo queria aprender virtud resueltamentc, $\mathrm{y}$ ir con mis buenos pensamientos adelante. Y que para esto me pussiessen à la escuela; pues sin leer, ni escriuir no se podia azer nada. Parecioles bien lo que decia aunque lo gruñeron vn rato entre los dos: mi madre se entro a dentro, y mi padre fue a rapar a vno (assi lo dixo el) no se si la barba, o la bolsa lo mas ordinario era vno, y otro. Yo me quede solo dando gracias a Dios por que me hizo hijo de padres tan zelosos de mi bien.

\section{III}

metilos en paz diçiendo que yo queria aprender virtud resueltamente y ir con mis buenos pensamientos adelante y que assi me pusiesen a la escuela pues que sin sauer leer y escreuir no se Podia hacer nada. Pareçioles bien lo que yo deçia aunque lo gruñeron vn rrato entre los dos mi madre se ocupo otro rrato en ensartar las muelas y $\mathrm{mi}$ padre fue a rrapar vna que assi dixo el no se si la barua o la volssa Yo me quede solo dando graçias a Dios por que me hiço de Padres tan viles y zelosos de mi vien.
Metílos yo en paz, diciendo que queria aprender virtud, resueltamente, y ir con mis buenos pensamientos adelante; y así, que me pusiese en la escuela, pues sin leer ni escribir no se podía hacer nada. Parecióles bien lo que yo decía, aunque lo gruñeron un rato entre los dos. Mi madre tornó a ocuparse en ensartar las muelas, y mi padre se tornó a ir fuera, no sé si a ocuparse en barba o en bolsa. Yo me quedé solo, dando gracias a Dios porque me hizo hijo de padres tan hábiles y celosos de mi bien.

\section{IV}

Metidos en paz, yo les dije que quería aprender virtud, resueltamente, y ir con mis buenos pensamientos adelante, y así que me pusiesen a la escuela, pues sin leer ni escribir no se podía hacer nada. Parecióles bien lo que yo decía, aunque lo gruñeron un rato entre los dos. Mi madre tornó a ocuparse en ensartar las muelas y mi padre fuć a rapar a uno -así lo dijo él- no sé si la barba o la bolsa; yo me quedé solo, dando gracias a Dios que me hizo hijo de padres tan hábiles y celosos de mi bien. 